\title{
Seawater reverse osmosis membrane fouling causes in a full scale desalination plant; through the analysis of environmental issues: raw water quality
}

\author{
Leila Rezaei $^{\circledR}$, Mohsen Dehghani $^{2^{\circledR}}$, Amir Hesam Hassani $^{3}{ }^{\circledR}$, Vali Alipour $^{*}{ }^{*}$ \\ ${ }^{1}$ Department of Environmental Sciences, Islamic Azad University, Qeshm International Branch, Qeshm, Iran \\ ${ }^{2}$ Department of Natural Resources and Environmental Sciences, Islamic Azad University, Bandar Abbas Branch ,Bandar Abbas, Iran \\ ${ }^{3}$ Department of Environmental Engineering, Science and Research Branch, Islamic Azad University, Tehran, Iran \\ ${ }^{4}$ Department of Environmental Health Engineering, School of Health, Hormozgan University of Medical Sciences, Iran
}

\begin{abstract}
Background: Membrane clogging is one of the most important problem for desalination plant operators in Iran, therefore, this study was conducted to investigate the main causes of this problem using field analysis.

Methods: In this study, six continuous membranes in a reverse osmosis (RO) pressure vessel under the 33-month service period (April 2017 to November 2019) were selected. The membranes were analyzed through visual evaluation of the outer and inner membrane surface, analyzing the damages and physical harms, oxidative stress tests, iron spot test, fouling chemical analysis using loss on ignition (LOI) tests, X-ray fluorescence (XRF), and Fourier-transform infrared (FTIR) spectroscopy.

Results: Particle size distribution in raw seawater $(\mathrm{EC}=55000 \mu \mathrm{s} / \mathrm{cm}$, turbidity $=11 \mathrm{NTU})$ was $66.4 \%$ smaller than $1 \mu$ and $28.3 \%$ between 1 to $1.9 \mu$ m. Physical damages were not seen on the membranes but telescopic damages were observed which was due to membrane fouling. Removal efficiencies of turbidity and silt density index (SDI) were $84 \%$ and $18 \%$, respectively. Membrane oxidation was also seen. Most of the sediments compositions on the membranes were $\mathrm{SiO}_{2}, \mathrm{Al}_{2} \mathrm{O}_{3}, \mathrm{MgO}$, and $\mathrm{Fe}_{2} \mathrm{O}_{3}$. Biological fouling was detected on the membranes surface.

Conclusion: Inaccurate use of chlorine neutralizer caused the residual chlorine to be present in the membrane entering water, which damaged the membrane. Accumulation of clogging agents on membrane surface showed malfunction of pretreatment function, therefore, revision of design and operation of units is necessary. Biological fouling is due to non-effective pre-chlorination of drinking water. Metallic compounds sedimentation on the membrane is due to improper use of anti-fouling chemicals. High SDI in the influent shows the need to change the cartridge filters.

Keywords: Seawater, Drinking, Chlorides, Particle size, Chloride, Spectroscopy, Fourier transform infrared, Iran

Citation: Rezaei L, Dehghani M, Hassani AH, Alipour V. Seawater reverse osmosis membrane fouling causes in a full scale desalination plant; through the analysis of environmental issues: raw water quality. Environmental Health Engineering and Management Journal 2020; 7(2): 119-126. doi: 10.34172/ EHEM.2020.14.
\end{abstract}

Article History:

Received: 9 April 2020

Accepted: 18 June 2020

ePublished: 6 July 2020

\section{Introduction}

Because of the increasing demand for water for municipal and industrial uses, water is a very valuable resource in Iran, especially in the southern regions during the warm period, because these regions face water shortage problems. The main aim of seawater desalination is actually to find new water resources to meet the needs of the communities $(1,2)$. Reverse osmosis (RO) process is one of advanced technologies in the field of seawater desalination because of its low investment cost and energy consumption $\left(0.5 \mathrm{kWh} / \mathrm{m}^{3}\right)$. As RO has been known as a suitable method of seawater desalination, so its utilization has been dramatically developed during the recent three decades (3-6).

The most important key factor for the cost-effective operation of the RO system is the existence of an appropriate pretreatment system. Fouling and clogging are the major challenges in membrane desalination system especially for seawater RO (SWRO). Impurities in the RO feed water can cause fouling, which reduce the membrane's efficiency, and as a result, decrease water quality and quantity and increase the operation costs (7). Membrane fouling means reduced membrane efficiency due to clogging caused by impure materials existing in the feed water, which have 
not been removed in the pretreatment phase. Fouling is the accumulation of colloidal matters on the surface of the membrane, which interferes with the passage of water through the membrane (8). RO membrane fouling occurs during the operation when feed water contains suspended particles, mud, and colloidal particles such as bacteria, soil, colloidal silica, and metal tools corrosion, aluminum sulfate, coagulating material, ferric chloride, and polyelectrolytes and so on. Among the above-mentioned materials, the common fouling agents include calcium carbonate silt, calcium, barium and strontium sulfates silt, clay minerals, and metal oxides ( $\mathrm{Fe}, \mathrm{MN}, \mathrm{Al}, \mathrm{Pb}$, etc). The intensity and type of the fouling depends on the quality of feed water and the rate of direct recycling. Usually, the fouling trend is ascendant and if no action is taken to remedy or stop it, fouling can endanger the performance of RO system in a short period of time (9), so early detection of fouling is critical. There are many methods and indicators for predicting the potential of feed water in creating fouling on the membrane surface of RO systems inducing silt density index (SDI), effluent turbidity, and particle counter tests. Membrane fouling not only reduces the quantity and quality of the produced water but also reduces the durability of membranes. Chemical rinsing is one of the ways to renew the membrane after fouling occurred (10). However, if rinsing process is delayed, fouling elimination will be very difficult, thus, analyzing and identifying the reasons of fouling are the most important and major efforts to find improving solutions. Another advantage of the analysis of the reasons is finding faults in the design or operation of the pre-treatment system. In addition, by analyzing the reasons, it is possible to find a suitable method for chemical cleaning of the membranes (11).

Many studies have been done in details regarding the fouling reasons through which one or two reasons have been identified, however, there are less global or comprehensive studies in this regard (12-19). In a study by Gutiérrez Ruiz et al, which is similar to the recent study, chemical composition and structure of fouling agents on the membrane surface were determined using the energy dispersive $\mathrm{X}$-ray microanalysis and scanning electronic microscopy. The results showed that the presence of calcium carbonate and excess colloidal silica intensifies the deposition on the membrane and clogging and decreases the permeate flux (17). In another study by Fayaz et al, the effect of disinfectants injection was evaluated to find the reduction of SDI efficiency, and it was revealed that injection of chlorine in the inlet of RO system can increase the lifetime of cartridge filters, and significantly, reduce the operation costs (19).

Given the importance of desalination plants to supply the water needed for communities and industries in southern Iran, it is important to pay attention to the technical and economic aspects of this category. On the other hand, due to the importance of membrane fouling and its effect on reducing production and increasing operating costs, it is more important to address this issue.

There are a variety of measurements and tests to assess the potential for clogging as well as damage to the RO membrane, the physical and chemical damages on the membrane are found using methylene blue. Fujiwara test (oxidative damage test) is applied to recognize the oxidation of the membrane surface using some halogens such as chlorine or bromide. If the membrane is oxidized, its surface color will change to red or pink. Iron spot test is used to recognize the existence of iron on the membrane surface. In this test, reagents are potassium hexacyanoferrate $\left(\mathrm{K}_{3} \mathrm{Fe}\left(\mathrm{CN}_{6}\right)\right)$ and hydrochloric acid. Other conventional tests including SDI, turbidity measurement of water, and tests of membrane surface inspection and particle counter, loss on ignition (LOI), $\mathrm{X}$-ray fluorescence (XRF), and Fourier-transform infrared (FTIR) spectroscopy can also be very helpful.

The aim of this study was to analyze the causes of membrane clogging to find improved and appropriate solutions in order to reduce the operational problems of SWRO plants.

\section{Materials and Methods}

In this descriptive-analytical study, it was focused on a large scale sea water desalination plant in south of Iran. The research was conducted in a 33-month period (from April 2017 to November 2019). Desalination plant was composed of 300 modules RO pressure vessels; simple diagram of desalination system is presented in Figure 1. In this study, six continuous polyamide membranes (SW30HRLE-400i, Dow-FilmTec Company) under the service RO pressure vessel were selected for analysis. The selected membranes were under the service for more than about 30 months and their technical specifications and utilization conditions were according to the manufacturer instructions (11). To identify the type of chemical fouling, membranes were sent to the laboratory to perform autopsy tests. Investigations and tests performed on the membranes included visual evaluation of outer and inner

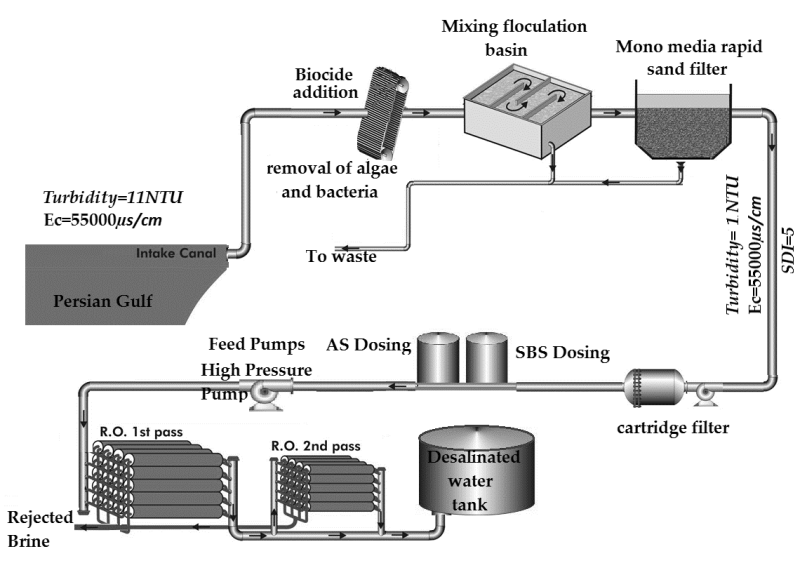

Figure 1. Schematic diagram of the studied desalination plant 
surface of the membrane, analysis of physical damages, oxidative damage tests, iron spot test, and chemical analysis of fouling using LOI tests, XRF, and FTIR spectroscopy. In addition, chemical quality of feed water was analyzed during the research period.

\section{SDI test}

To implement the test, the membrane was placed inside a container, and then, the inlet valve was opened. By setting the regulator, the input pressure applied to the system was set on 30 psi (2.1 bar). To start the test, first a $500-\mathrm{mL}$ beaker was put under the water outlet vent passed through the membrane to collect it, and then, the outlet vent was turned on, and simultaneously, the time during which the beaker was getting filled up to $500 \mathrm{~mL}$ was measured by a chronometer. The test continued for another 15 minutes from the first time of turning on the vent (including the time of beaker filling) and after another 15 minutes again, the beaker-filling time up to $500 \mathrm{~mL}$ was recorded. Then, to calculate the SDI, the following formula was used, according to the standard code of ASTM-D4189:

$\mathrm{SDI}=\left(1-\frac{t i}{t f}\right) * \frac{100}{T}$

Where $T$ is the total time of the test (usually 15 minutes), $t_{i}$ is the preliminary time of collecting $500 \mathrm{ml}$ of passed water, and $t_{f}$ is the secondary time of collecting $500 \mathrm{~mL}$ output water (20).

\section{Turbidity test}

In this research, a turbidity-meter (HACH-2100Q) was used to measure the turbidity of water.

\section{Membrane surface inspection and tests}

To the autopsy test, first the membrane was taken out of pressure vessel so that no environmental pollution was added to the membrane. Then, the membrane was put inside a waterproof plastic bag, and immediately, transferred to the autopsy laboratory. In the laboratory, the membrane was weighed and visually checked for superficial damages, fractures and/or telescopic phenomenon. A membrane case was cut longitudinally and four slices of outer layers were cut symmetrically. After cutting the outer layer, the intermingled layers of the membrane were opened carefully in a way that the surface of the membrane was not harmed. Sampling was performed from three different parts including membrane surface, spacer layer, permeate water transfer layer (20).

Membrane damage test using methylene blue

In this test, first a piece of membrane was cut and placed on a plain surface. Then, methylene blue $0.05 \%$ was poured on the feed water entrance of the membrane. In this case, if the membrane was damaged, the color of the other side of the membrane plain would change into blue in the damaged areas (20).
Fujiwara test

To perform the Fujiwara test in the laboratory, at first $2 \mathrm{~mL}$ of sodium hydroxide $20 \%$ was mixed with $1 \mathrm{~mL}$ of pyridine dissolved mixture. Then, the samples of membrane $\left(1 \mathrm{~cm}^{2}\right)$ were soaked in the mixture, and then, left in the bathroom containing $100^{\circ} \mathrm{C}$ water for 2 minutes (20).

Iron spot test

To perform the iron spot test, first a piece of the membrane sheet was cut and put on a plain surface. Then, few drops of a mixture of potassium ferricyanide solution and chloridric acid were added to the surface of membrane, and the color of the membrane surface changed to red, indicating the existence of iron (20).

\section{Particle counter test}

To do the particle counter test, prior to putting the sample in the device in order to homogenize the sample, it was shaken for 2 minutes and after homogenizing the outer surface of the glass container, it was completely cleaned. Then, the sample inside the device was transferred to the particle counter (Abakus model), and particle size level was set using software, in 17 size levels $(1-20 \mu \mathrm{m})$ were considered. Based on the fracture of light passing through the particle against the identifier and using a software connected to the device, different values and sizes, as well as how the particles are distributed in the sample were determined (20).

Loss on ignition test

To implement the LOI test, first $1 \mathrm{~g}$ of the sampled membrane surface was well pulverized and mixed, then, it was examined and weighed in the laboratory. Afterwards, the samples were put inside a dryer at a temperature of 104$110^{\circ} \mathrm{C}$. Weight loss of the sample in this step was calculated based on the loss of humidity at two temperatures of 105 and $950^{\circ} \mathrm{C}$, then, the rate of LOIT was estimated via Eq. (1) (20):

$L O I T=\pi r 2=100(W S 105-D W 950) / W S(1)$

Where WS is the original sample weight, DW105 and DW950 are dried sample weight at temperatures of 105 and $950^{\circ} \mathrm{C}$, respectively.

\section{$\mathrm{X}$-ray fluorescence}

The test of XRF was done to determine the membranes chemical compositions, which was accomplished according to the reference standard (ASTM E1621-05) at the laboratory ambient temperature of $25^{\circ} \mathrm{C}$ and humidity rate of $30 \%$ at test time. Preparation of the sample collected from the surface of the membranes was along with crushing, and the results were based on the weight percentage of elements (20). 
Fourier transform infrared spectroscopy

In FTIR test for the inspected and analyzed membranes, pyrolysis and preparation of the IR spectrum were done according to the standard code of ASTM E1252-07, while the laboratory ambient temperature and humidity rate at test time were $25^{\circ} \mathrm{C}$ and $30 \%$, respectively. This test was performed using an FTIR spectrometer (BOMEM MBSeries) (20).

\section{Results}

Chemical quality of the feed water

Due to the high impact of water quality parameters on membrane clogging, the results of these parameters are presented in Table 1. The chemical quality parameters of the feed water in desalination system were measured during the study, and the results are presented in Table 1.

Membrane surface evaluation and tests

The results obtained from the inner surface of the membrane show that the sediments concentrations had a decreasing trend from the membranes 1 to 6 , so the concentration of sediments accumulated in the inlet part was higher than those accumulated in the outlet part. In all membranes, except one, the pollution accumulation rate was high especially in two points; the connection point to permeated water pipe and at the end of the vessel cover connection. In membrane 4 , the pollution accumulation was observed only in one side of membrane, which was due to long-term water stagnation in the membrane. Physical injuries test was also performed to detect membrane damages and physical injuries, including lacerations and abrasions, and the results show that all 6 membranes had no physical damages (Figure 2).

The Fujiwara test was performed to recognize the rate of destructions and physical damages of the membranes including tearing, scratching and so on, and no physical damage was found. The Fujiwara test showed that there was no change in the color of the membranes to pink in the whole under-the-study membranes, except membrane 3. This change, however, was significant in membrane 3 , therefore, sampling from some layers of the membrane was performed again and the test was repeated, and the results showed that membrane 3 was a little oxidized.
The iron spot test was done to find the presence of iron particles on the surface of the membrane, during which the whole layers of the membrane were analyzed and tested. Observing red color confirmed the presence of iron, the results are shown in Figure 3.

SDI and particles counting of the feed seawater

The results of SDI analysis in the influent and effluent of cartridge filter are presented in Figure 4.

The average of seawater pretreatment system efficiency for turbidity and SDI reducing were $84 \%$, and $18 \%$ respectively. The average efficiency of cartridge filters in the turbidity and SDI reducing of the pretreatment effluent water was $45 \%$ and $20 \%$ respectively. Considering desirable turbidity $(\mathrm{NTU}<1)$ and SDI $(<3)$ recommended by the membranes manufacturers for the RO systems, the turbidity and SDI reduction level was not enough to meet the recommended levels.

As the SDI values of cartridge filter effluent were relatively high, there is the possibility of particles reaching the membrane and their accumulation on it. Therefore, particle counting experiments were performed, the results of particle counting before and after pretreatment system

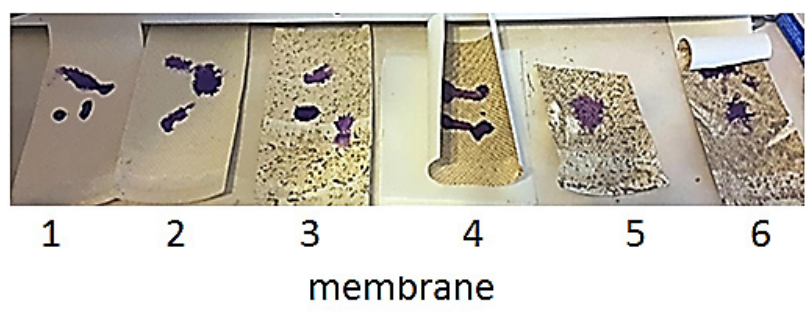

Figure 2. The results of methylene blue test on the membranes surfaces.

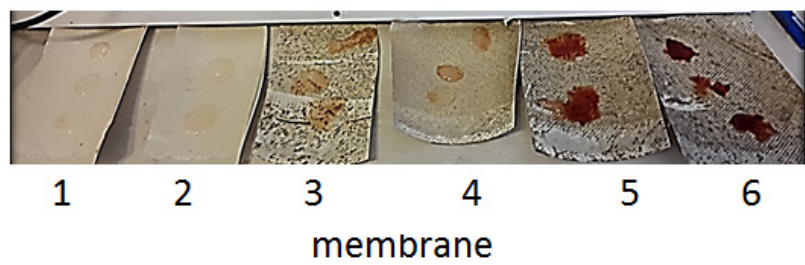

Figure 3. The results of iron spot test on the surface of the membranes

Table 1. Average and standard deviation of feed water parameters measured during the study period

\begin{tabular}{|c|c|c|c|c|c|c|c|c|c|c|c|}
\hline \multirow{2}{*}{ Year } & \multirow{2}{*}{$\mathrm{pH}$} & EC & MAlk & TDS & TSS & $\mathrm{SO}_{4}$ & $\mathrm{Na}$ & K & $\mathrm{Ca}$ & $\mathrm{Mg}$ & $\mathrm{SiO}_{2}$ \\
\hline & & $\mu \mathrm{s} / \mathrm{cm}$ & $\mathrm{mg} / \mathrm{L} \mathrm{CaCO}_{3}$ & $\mathrm{mg} / \mathrm{L}$ & $\mathrm{mg} / \mathrm{L}$ & $\mathrm{mg} / \mathrm{L}$ & $\mathrm{mg} / \mathrm{L}$ & $\mathrm{mg} / \mathrm{L}$ & $\mathrm{mg} / \mathrm{L}$ & $\mathrm{mg} / \mathrm{L}$ & $\mathrm{mg} / \mathrm{L}$ \\
\hline \multirow{2}{*}{2017} & $8 \pm$ & $54889 \pm$ & $130 \pm$ & $38961 \pm$ & $4 \pm$ & $3600 \pm$ & $11033 \pm$ & \multirow{2}{*}{$281 \pm 8.2$} & \multirow{2}{*}{$432 \pm 35.2$} & \multirow{2}{*}{$1325 \pm 262.4$} & \multirow{2}{*}{$0.2 \pm 0.1$} \\
\hline & 0.1 & 445.0 & 2.6 & 710.9 & 2.7 & 135.3 & 1145.1 & & & & \\
\hline \multirow{2}{*}{2018} & $7.9 \pm$ & $56826 \pm$ & $203 \pm$ & $38478 \pm$ & $4.5 \pm$ & $3482 \pm$ & $12207 \pm$ & \multirow{2}{*}{$460 \pm 7.4$} & \multirow{2}{*}{$613 \pm 40.2$} & \multirow{2}{*}{$3097 \pm 211.2$} & $0.11 \pm$ \\
\hline & 0.1 & 507.6 & 5.1 & 578.3 & 2.3 & 162.5 & 2019.3 & & & & 0.0 \\
\hline \multirow{2}{*}{2019} & $8 \pm$ & $55000 \pm$ & $135 \pm$ & $35500 \pm$ & $4.42 \pm$ & $3500 \pm$ & $12000 \pm$ & \multirow{2}{*}{$350 \pm 8.5$} & \multirow{2}{*}{$500 \pm 41.5$} & \multirow{2}{*}{$1850 \pm 195.7$} & $0.22 \pm$ \\
\hline & 0.1 & 491.2 & 3.4 & 602.1 & 2.6 & 147.0 & 1363.4 & & & & 0.0 \\
\hline
\end{tabular}




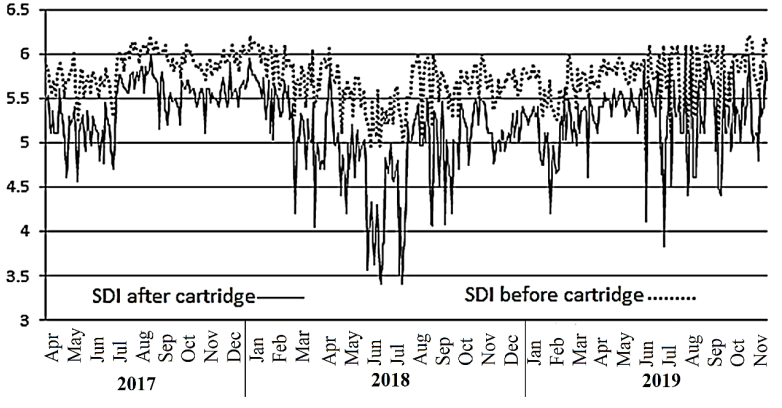

Figure 4. SDI before and after pretreatment during the study period.

are presented in Table 2.

As shown in Table 2, almost $66.4 \%$ of the particles exist in the seawater are limited to an area smaller than $1 \mu \mathrm{m}$ and the size of $28.3 \%$ of the particles was between 1 and $1.9 \mu \mathrm{m}$.

Composition of fouling agents on the surface of membranes Determination of the LOI

The results of the LOI method, as the estimated amounts of oxidized organic materials, are presented in Figure 5.

\section{Analysis of XRF and FTIR spectroscopy}

The results of LOI test showed that there were organic materials on the membrane layers. Therefore, infrared spectroscopy was used to determine the structure of materials and measure the type of chemicals based on the radiation absorption and analysis of the seismic leaps of molecules and polyatomic ions. The results of XRF analysis are presented in Tables 3 and 4 . The results of

Table 2. Average number of particles in $10 \mathrm{cc}$ of the seawater before and after pretreatment

\begin{tabular}{|c|c|c|}
\hline Size $(\mu)$ & Before Pretreatment & After Pretreatment \\
\hline 1 & 701407 & 32429 \\
\hline 1.9 & 299443 & 10295 \\
\hline 4.9 & 45612 & 1183 \\
\hline 8.2 & 4305 & 119 \\
\hline 9 & 2657 & 75 \\
\hline 10.4 & 996 & 28 \\
\hline 11 & 808 & 23 \\
\hline 12 & 550 & 17 \\
\hline 13 & 347 & 11 \\
\hline 14 & 203 & 7 \\
\hline 15 & 108 & 5 \\
\hline 16 & 83 & 4 \\
\hline 17 & 67 & 3 \\
\hline 18 & 52 & 2 \\
\hline 19.6 & 33 & 1 \\
\hline 19.7 & 33 & 1 \\
\hline 20 & 31 & 1 \\
\hline
\end{tabular}

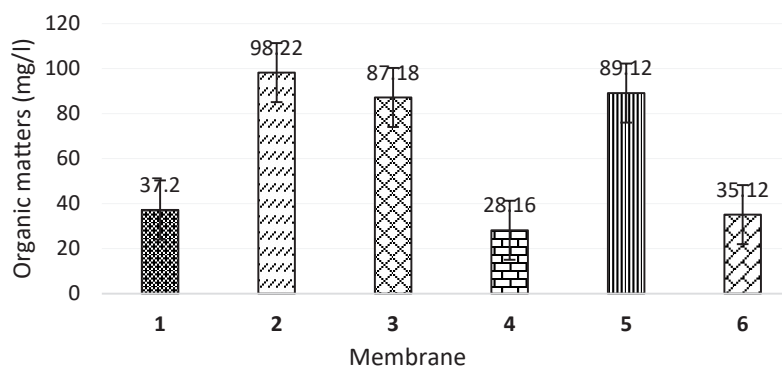

Figure 5. The density of organic materials measured in the membranes.

FTIR for determining the type of samples taken from the surface of membranes 1 to 5 are presented in Figure 6 .

\section{Discussion}

Visual evaluation

Based on the visual evaluation, due to the membranes fouling, they were not able to allow to pass enough water through their surface, which led to the head loss and increased pressure. The telescopic shape of membranes, during the operation, is caused by the mechanical stress resulting from the pressure difference, especially at the moment of starting the system.

\section{Sediments analysis}

The main sediments compositions on the membrane surface were $\mathrm{SiO}_{2}, \mathrm{Al}_{2} \mathrm{O}_{3}, \mathrm{MgO}$, and $\mathrm{Fe}_{2} \mathrm{O}_{3}$, and most of the silt formed on the membrane was formed due to the existence of $\mathrm{SiO}_{2}$, which are consistent with the results of the study by Karabelas et al (21). The most common minerals that forms the colloidal solids is aluminum silica with particles sized between 0.3 and $1 \mu \mathrm{m}$ and colloidal metal oxidations like iron, aluminum, and magnesium. Totally, about $95 \%$ of the particles in the seawater was smaller than $1.9 \mu \mathrm{m}$, so the efficiency of the pretreatment

Table 3. Chemical composition of elements in the sediments accumulated on the studied membranes detected by XRF test

\begin{tabular}{lcccccc}
\hline \multirow{2}{*}{ Element } & \multicolumn{5}{c}{$\begin{array}{c}\text { Weight percentage of elements in the sediments } \\
\text { accumulated on membranes 1-6 }\end{array}$} \\
\cline { 2 - 7 } & $\# 1$ & $\# \mathbf{2}$ & $\# 3$ & $\# 4$ & $\# 5$ & $\# 6$ \\
\hline $\mathrm{Na}$ & 1.2 & 1.1 & 0.9 & 4.3 & 1 & 0.8 \\
$\mathrm{Mg}$ & 5.8 & 5.5 & 6.1 & 6 & 6.9 & 7.3 \\
$\mathrm{Al}$ & 6 & 5.8 & 6.2 & 6.1 & 7.2 & 7.3 \\
$\mathrm{Si}$ & 19.1 & 18.4 & 19.5 & 18.8 & 21.9 & 21.9 \\
$\mathrm{P}$ & 0.1 & 0.09 & 0.09 & 0.05 & 0.05 & 0.05 \\
$\mathrm{~S}$ & 0.24 & 0.22 & 0.021 & 0.23 & 0.14 & 0.14 \\
$\mathrm{Cl}$ & 0.34 & 0.27 & 0.34 & 3.9 & 0.27 & 0.19 \\
$\mathrm{~K}$ & 2 & 2 & 2.2 & 2 & 2.3 & 2.3 \\
$\mathrm{Ca}$ & 2.2 & 2.4 & 1.8 & 0.54 & 0.49 & 0.44 \\
$\mathrm{~T}$ & 0.31 & 0.3 & 0.31 & 0.29 & 0.33 & 0.32 \\
$\mathrm{Fe}$ & 6.2 & 6 & 6.7 & 5.4 & 6.4 & 6.4 \\
\hline
\end{tabular}


Table 4. Chemical composition of the sediments accumulated on the study membranes detected by XRF test

\begin{tabular}{|c|c|c|c|c|c|c|}
\hline \multirow{2}{*}{$\begin{array}{l}\text { Element/ } \\
\text { compound }\end{array}$} & \multicolumn{6}{|c|}{$\begin{array}{l}\text { Weight percentage of elements in the sediments } \\
\text { accumulated on membranes } 1-6\end{array}$} \\
\hline & 1 & 2 & 3 & 4 & 5 & 6 \\
\hline $\mathrm{Na}_{2} \mathrm{O}$ & 1.2 & 1.4 & 1.2 & 5.8 & 1.3 & 1.1 \\
\hline MgO & 9.5 & 9.2 & 10.1 & 9.9 & 11.5 & 12.1 \\
\hline $\mathrm{Al}_{2} \mathrm{O}_{3}$ & 11.3 & 11 & 11.8 & 11.6 & 13.5 & 13.8 \\
\hline $\mathrm{SiO}_{2}$ & 40.9 & 39.5 & 41.7 & 40.3 & 46.9 & 46.8 \\
\hline $\mathrm{P}_{2} \mathrm{O}_{4}$ & 0.24 & 0.21 & 0.2 & 0.12 & 0.12 & 0.12 \\
\hline $\mathrm{SO}_{3}$ & 0.6 & 0.55 & 0.54 & 0.57 & 0.36 & 0.34 \\
\hline $\mathrm{Cl}$ & 0.34 & 0.27 & 0.34 & 3.9 & 0.27 & 0.19 \\
\hline $\mathrm{K}_{2} \mathrm{O}$ & 2.5 & 2.4 & 2.6 & 2.5 & 2.8 & 2.7 \\
\hline $\mathrm{CaO}$ & 3 & 3.3 & 2.5 & 0.75 & 0.69 & 0.62 \\
\hline $\mathrm{TiO}_{2}$ & 0.52 & 0.5 & 0.52 & 0.48 & 0.55 & 0.54 \\
\hline $\mathrm{Fe}_{2} \mathrm{O}_{3}$ & 8.9 & 8.5 & 9.6 & 7.8 & 9.1 & 9.1 \\
\hline $\mathrm{Br}$ & 0.16 & 0.14 & 0.12 & 0.07 & 0.06 & 0.05 \\
\hline LOI & 29.37 & 22.98 & 18.87 & 16.28 & 12.89 & 12.35 \\
\hline
\end{tabular}

system in removing the tinier particles was less, therefore, the pretreatment system could transmit lots of particles tinier than $1.9 \mu \mathrm{m}$, which could not be caught in the cartridge filters $(5 \mu \mathrm{m})$; the particles accumulation on the surface of the membranes led to colloidal fouling.
$\mathrm{XRF}$ test analysis

The results of XRF analysis show that elements like silica, aluminum, iron, and magnesium are more accumulated on the membrane surface. When some $\mathrm{Si}^{4+}$ ions are replaced by $\mathrm{Al}^{3+}$ ions, aluminum silica is produced. To replace each $\mathrm{Si}^{4+}$ ion with an $\mathrm{Al}^{3+}$ ion, the ionic bar must be equalized. This equalization occurs by taking other positive ions like iron, magnesium, and other cations (22). This is completely consistent with the results obtained through the visual evaluation, indicating the presence of aluminum silica and metal oxidations on the membranes surface. Also, the results of FTIR analysis show the existence of some peaks in the $900-1100 \mathrm{~cm}^{-1}$ and 1170 $1183 \mathrm{~cm}^{-1}$ boundaries, indicating that there were factual groups of $\mathrm{Si}-\mathrm{O}$ and colloidal silica on the surface of the membrane (23).

Loss on ignition analysis

Based on the results of LOI test, membranes 1 and 2 had the most percentages of the organic materials and membrane 6 had the least ones. This condition was raised because of $18 \%$-weight (in average) organic fouling on the surface of the studied membranes. Organic fouling occurs because of dissolved particles in the feed water of the RO system, which tends to stick to the surface of the membrane, including oils, proteins, polysaccharides, and anti-foam substances. In this type of fouling, a jelly

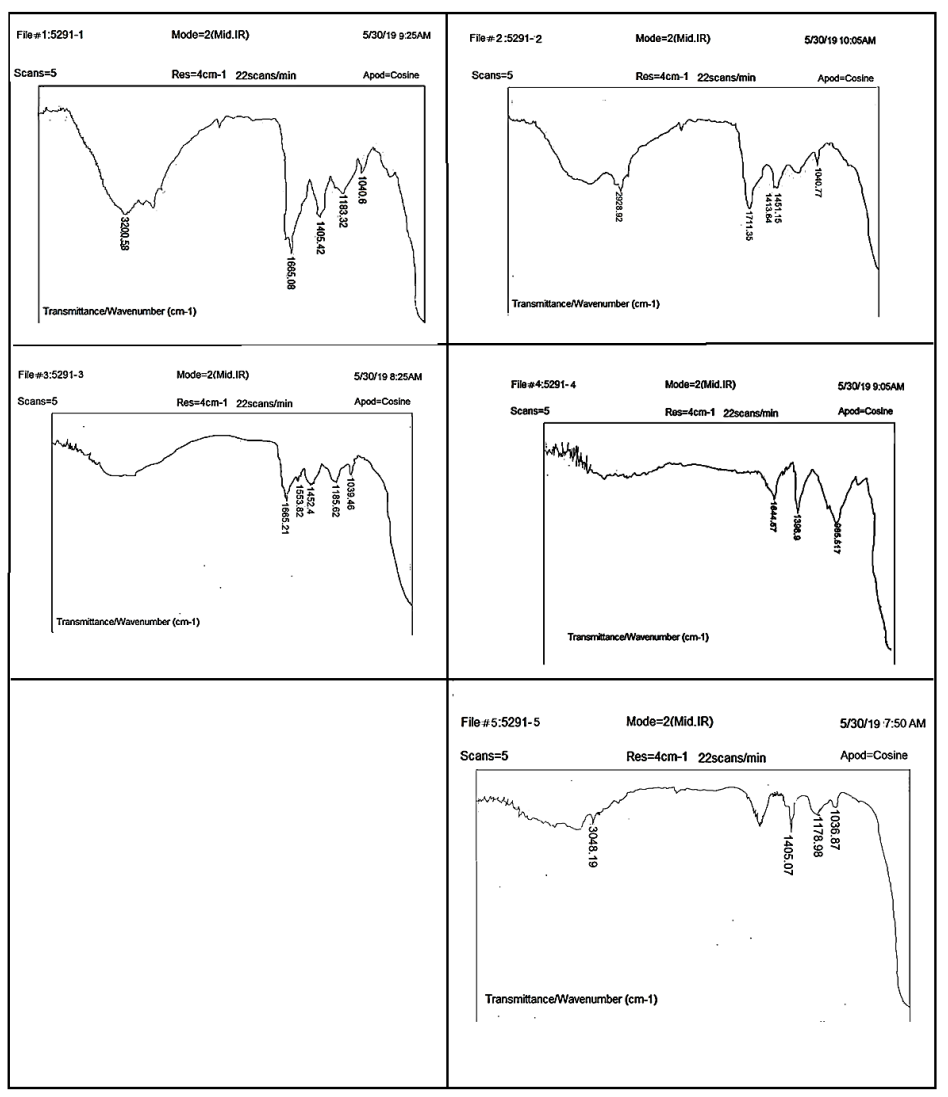

Figure 6. Results of FTIR test used for determining organic compounds deposited on the surface of the studied membranes (membranes 1 to 5 ). 
layer of organic materials will be formed on/in the pores of membrane (24).

\section{FTIR spectroscopy analysis}

The results of FTIR spectroscopy analysis show the existence of peaks in the range of $1040 \mathrm{~cm}^{-1}$, which is indicator of the alcoholic $\mathrm{C}-\mathrm{O}$ agent group derived from the polysaccharides. The existence of microorganisms and polysaccharides in their shells, indicates the biological fouling on the membrane surface (23). Therefore, the main concern is that a part of this fouling has a biological source. The peaks are related to $1400-1450 \mathrm{~cm}^{-1}$ area, which is indicating the presence of $\mathrm{C}-\mathrm{N}$ and $\mathrm{N}-\mathrm{H}$ agent groups, and therefore, the presence of Amid 3 and protein. The peaks in $1500-1551 \mathrm{~cm}^{-1}$ area introduce C-N and $\mathrm{N}-\mathrm{H}$ agent groups, indicating the presence of Amid 2 and protein. Also, the peaks in $1640-1660 \mathrm{~cm}^{-1}$ region is indicate the agent groups of $\mathrm{N}-\mathrm{H}$ and Amid A, indicating the presence of protein. Given that there is ribosome (source of protein) in the structure of the bacteria, having this composition also confirms the existence of a biological fouling on the surface of a membrane. Moreover, regions of $1735-1745 \mathrm{~cm}^{-1}$ introduce the agent group $(\mathrm{C}=\mathrm{O})$ of carboxylic acid, which shows the presence of humic acid. Humic acid is one of the most clearly known materials in organic fouling.

About $20 \%$ of the deposits accumulated on the membrane were elliptical materials. This condition indicates a high TOC level in the raw water. Therefore, reducing the TOC level in raw water using one of the TOC removal methods (effective pre-chlorination, improving coagulation and flocculation processes, using activated carbon filters) should be considered.

\section{Conclusion}

Membrane clogging is the most important problem for SWRO operators in Iran, so in this study, the specific causes of this problem were investigated using field analysis.

The most important causes of clogging and fouling of the studied desalination membranes were sediments, organic matter, and biological agents, respectively. Sediments originated from colloidal materials were mainly silt, clay, silica, and aluminum. In addition to the colloidal sediments that formed the most intense part of the sediments on the surface of the membranes under study, organic (protein, polysaccharides, and humic acids) and biological sediments are the other causes of the decrease in the membranes function and efficiency.

Incomplete elimination of the free chloride remained from the disinfection phase, was another leading cause of membrane damage, which oxidized it, it means that chlorine neutralizing agent was not applied properly. Lack of effective system can lead to the accumulation of clogging agents on membrane surface, so revision of design and operation of pretreatment unit's, especially coagulation and filtration processes, is a useful way to reduce the problem. The presence of high SDI in the water pass across the membrane is a definite sign of the need to modify the cartridge filters. The presence of biological fouling on the membrane surface is due to non-effective pre-chlorination in intake unit, so more attention should be paid to this unit. Symptoms of membrane oxidation are also due to the non-effective removal of residual chlorine and other oxidizing chemicals in the water before reaching the membrane, so adding chlorine neutralizer and antifouling chemicals should be also reconsidered.

\section{Acknowledgements}

The authors would like to express their sincere gratitude to Hormozgan University of Medical Sciences (HUMS) for their cooperation.

\section{Ethical issues}

The authors hereby certify that all data collected during the research are as expressed in the manuscript, and no data from the study has been or will be published elsewhere separately. The study protocols were approved by the Ethics Committee of Hormozgan University of Medical Sciences (HUMS) (Ethical code: HUMS.REC.1396.174).

\section{Competing interests}

The authors declare that they have no conflict of interests.

\section{Authors' contributions}

All authors were involved in data collection, analysis, and interpretation. They also reviewed, refined, and approved the manuscript.

\section{References}

1. Freire-Gormaly M, Bilton AM. Impact of intermittent operation on reverse osmosis membrane fouling for brackish groundwater desalination systems. J Memb Sci 2019; 583: 220-30. doi: 10.1016/j.memsci.2019.04.010.

2. Matin A, Rahman F, Shafi HZ, Zubair SM. Scaling of reverse osmosis membranes used in water desalination: Phenomena, impact, and control; future directions. Desalination 2019; 455: 135-57. doi: 10.1016/j.desal.2018.12.009.

3. Alipour V, Mahvi AH, Rezaei L. Quantitative and qualitative characteristics of condensate water of home air-conditioning system in Iran. Desalin Water Treat 2015; 53(7): 1834-9. doi: 10.1080/19443994.2013.870724.

4. Hacıfazlığlu MC, Parlar İ, Pek TÖ, Kabay N. Evaluation of chemical cleaning to control fouling on nanofiltration and reverse osmosis membranes after desalination of MBR effluent. Desalination 2019; 466: 44-51. doi: 10.1016/j. desal.2019.05.003.

5. Mehrgan MR, Mahdiraji HA, Binaee S, Alipour V, Razavi Haji Agha SH. Modeling of environmental aspects related to reverse osmosis desalination supply chain. Environ Health Eng Manag 2020; 7(1): 31-40. doi: 10.34172/ehem.2020.05.

6. Anis SF, Hashaikeh R, Hilal N. Reverse osmosis pretreatment technologies and future trends: a comprehensive review. Desalination 2019; 452: 159-95. doi: 10.1016/j. 
desal.2018.11.006.

7. Goh PS, Lau WJ, Othman MH, Ismail AF. Membrane fouling in desalination and its mitigation strategies. Desalination 2018; 425: 130-55. doi: 10.1016/j.desal.2017.10.018.

8. Jiang W, Xu X, Lin L, Wang H, Shaw R, Lucero D, et al. A pilot study of an electromagnetic field for control of reverse osmosis membrane fouling and scaling during Brackish groundwater desalination. Water 2019; 11(5): 1015. doi: 10.3390/w11051015.

9. Quay AN, Tong T, Hashmi SM, Zhou Y, Zhao S, Elimelech M. Combined organic fouling and inorganic scaling in reverse osmosis: role of protein-silica interactions. Environ Sci Technol 2018; 52(16): 9145-53. doi: 10.1021/acs. est.8b02194.

10. Wang S, Xiao K, Huang X. Characterizing the roles of organic and inorganic foulants in RO membrane fouling development: the case of coal chemical wastewater treatment. Sep Purif Technol 2019; 210: 1008-16. doi: 10.1016/j.seppur.2018.09.062.

11. Dow. Water Solutions. Belgium: Dow; 2010. No. 60900071-0109.

12. Li X, Yan D, An G, Jing D, Li J. Fouling and cleaning of reverse osmosis membranes during municipal tap water treatment on a pilot-scale plant. Journal of Water Sustainability 2011; 1(1): 139-51.

13. Singh V, Das A, Das C, Pugazhenthi G, Srinivas M, Senthilmurugan S. Fouling and cleaning characteristics of reverse osmosis (RO) membranes. J Chem Eng Process Technol 2015; 6(4): 1000244. doi: 10.4172/21577048.1000244

14. Yu T, Meng L, Zhao Q, Shi Y, Hu HY, Lu Y. Effects of chemical cleaning on RO membrane inorganic, organic and microbial foulant removal in a full-scale plant for municipal wastewater reclamation. Water Res 2017; 113:1-10. doi: 10.1016/j.watres.2017.01.068.

15. Melián-Martel N, Sadhwani JJ, Malamis S, OchsenkühnPetropoulou M. Structural and chemical characterization of long-term reverse osmosis membrane fouling in a full scale desalination plant. Desalination 2012; 305: 44-53. doi: 10.1016/j.desal.2012.08.011.

16. Yin W, Li X, Suwarno SR, Cornelissen ER, Chong TH. Fouling behavior of isolated dissolved organic fractions from seawater in reverse osmosis (RO) desalination process. Water Res 2019; 159: 385-96. doi: 10.1016/j. watres.2019.05.038.

17. Gutiérrez Ruiz S, López-Ramírez JA, Hassani Zerrouk M, Egea-Corbacho Lopera A, Quiroga Alonso JM. Study of reverse osmosis membranes fouling by inorganic salts and colloidal particles during seawater desalination. Chin J Chem Eng 2020; 28(3): 733-42. doi: 10.1016/j. cjche.2019.10.004.

18. Tong T, Wallace AF, Zhao S, Wang Z. Mineral scaling in membrane desalination: mechanisms, mitigation strategies, and feasibility of scaling-resistant membranes. J Memb Sci 2019; 579: 52-69. doi: 10.1016/j.memsci.2019.02.049.

19. Fayaz SM, Mafigholami R, Razavian F, Ghasemipanah $\mathrm{K}$. Control of silt density index of osmosis membranes through chlorine injection and its effect on cartridge filter replacement period. Jundishapur J Health Sci 2019; 11(1): e84966. doi: 10.5812/jjhs.84966.

20. Jin Y, Lee H, Park C, Hong S. ASTM standard modified fouling index for seawater reverse osmosis desalination process: status, limitations, and perspectives. Sep Purif Rev 2020; 49(1): 55-67. doi: 10.1080/15422119.2018.1515777.

21. Karabelas AJ, Mitrouli ST, Kostoglou M. Scaling in reverse osmosis desalination plants: a perspective focusing on development of comprehensive simulation tools. Desalination 2020; 474: 114193. doi: 10.1016/j. desal.2019.114193.

22. Saffarimiandoab F, Yavuzturk Gul B, Erkoc-Ilter S, Guclu S, Unal S, Tunaboylu B, et al. Evaluation of biofouling behavior of zwitterionic silane coated reverse osmosis membranes fouled by marine bacteria. Prog Org Coat 2019; 134: 30311. doi: 10.1016/j.porgcoat.2019.05.027.

23. Wang S, Mu C, Xiao K, Zhu X, Huang X. Surface charge regulation of reverse osmosis membrane for anti-silica and organic fouling. Sci Total Environ 2020; 715: 137013. doi: 10.1016/j.scitotenv.2020.137013.

24. Im SJ, Jeong G, Jeong S, Cho J, Jang A. Fouling and transport of organic matter in cellulose triacetate forwardosmosis membrane for wastewater reuse and seawater desalination. Chem Eng J 2020; 384: 123341. doi: 10.1016/j. cej.2019.123341. 